\title{
Cold-Adapted Recombinants of Influenza A Virus in MDCK Cells
}

\author{
I. Development and Characterization of A/Ann Arbor/6/60 $\times$ A/Alaska/6/77 \\ Recombinant Viruses
}

\author{
TAKATO ODAGIRI, ${ }^{1}$ DAN C. DEBORDE, AND HUNEIN F. MAASSAB ${ }^{2}$
}

Department of Epidemiology, School of Public Health, The University of Michigan, 109 Observatory Street, Ann Arbor, Michigan 48109

Received October 19, 1981; accepted February 11, 1982

\begin{abstract}
Recombinant influenza viruses made at 25 and $33^{\circ}$ in Madin-Darby canine kidney (MDCK) cells using the cold-adapted A/Ann Arbor/6/60 virus and the wild-type A/ Alaska/6/77 virus were biologically and genetically analyzed. Eight recombinants were separated into two phenotypic groups based on cold-adapted (ca) and temperature-sensitive (ts) markers: ca and ts, ca and non-ts. The ca recombinants showed different degrees of cold adaptibility (DOCA) and different patterns of virus growth at $25^{\circ}$. All recombinants contained at most three genes from the cold variant A/Ann Arbor/6/60 virus (triple-gene recombinant) and most contained two or one gene from the cold variant parent (double-gene and single-gene recombinants, respectively). Further, the same three genes, RNA2, RNA3, and RNA5 (NA) were the only ca A/Ann Arbor/6/60 genes found in the various recombinants. Two clones contained all three $A / A n n$ Arbor $/ 6 / 60$ genes and were both cold-adapted (ca) and temperature-sensitive (ts). All other recombinant clones were ca and non-ts, and contained RNA2 and/or RNA5 (NA). Each set of singlegene ca recombinants correlated with a different, but specific cold-adapted characteristic exhibited by their growth curves at $25^{\circ}$. Single-gene recombinants containing only the RNA2 of A/Ann Arbor/6/60 virus showed rapid growth early in infection and intermediate final virus yield (between the titer of virus yield for the ca A/Ann Arbor/6/60 virus and the wild-type $A / A l a s k a / 6 / 77$ virus; while the single-gene recombinant containing only the RNA5 (NA) of A/Ann Arbor/6/60 virus showed slow growth early in infection, but a high final virus yield (equivalent to that of the ca A/Ann Arbor/6/60 parent). The double-gene recombinant containing both these genes showed both rapid growth early in infection and a high final virus yield. Thus, cold adaptation can be transferred to recombinant viruses by at least two independent genes each of which can confer the cold-adaptive property by its own pathway. The genetic basis for temperature sensitivity involves both RNA2 and RNA3, but remains ambiguous in the absence of a single-gene recombinant containing only RNA3 of the cold variant.
\end{abstract}

\section{INTRODUCTION}

The influenza virus genome consists of eight distinct RNA segments each of which codes for at least one polypeptide, the $M$ and NS genes having been shown to encode two polypeptides each (Palese and Shul-

\footnotetext{
${ }^{1}$ Present address: Department of Bacteriology, Tohoku University, School of Medicine, 2-1 Seiryomachi Sendai 980, Japan.

${ }^{2}$ To whom reprint requests should be addressed.
}

man, 1976; Pons, 1976; Inglis et al., 1976; Scholtissek et al., 1976; Almond et al., 1977; Lamb et al., 1978; and Palese et al., 1981). Recombinant viruses are readily produced by reassortment of RNA segments when two influenza viruses are grown together in the same cells. Thus, it is possible to develop attenuated influenza recombinant viruses suitable for use as live vaccines, using recent epidemic wild type viruses in combination with an apathogenic master strain capable of donating genes confer- 
ring attenuation. Using attenuated donor viruses to produce recombinant live vaccine strains has two advantages: (1) the vaccine lines can be prepared in a short time period due to the ease of recombination, and (2) the recombinants can be assessed for probable attenuation by laboratory characterization of phenotypic and genetic markers, prior to evaluation in humans. Confidence that the laboratory assessment can successfully predict attenuation demands a complete understanding of the relationship between the genetic markers and attenuation.

A/Ann Arbor/6/60 cold-adapted virus was produced by serial passages in primary chick kidney (PCK) cells by gradually lowering the temperature of incubation to $25^{\circ}$ which is restrictive for growth of wild-type influenza A viruses (Maassab, 1969, 1970, 1975). After adaptation at the lower temperature A/Ann Arbor/6/60 virus was found to have acquired temperature-sensitive (ts) mutation(s) with shutoff temperatures at 37 or $38^{\circ}$ in PCK cells and primary rhesus monkey kidney cells (Maassab, 1967, 1969, 1970; Maassab et al., 1969; Spring et al., 1977a, b) as well as coldadaptation (ca) mutation(s). In addition, the cold-adapted viruses were found to be attenuated when administered to animals and humans (Maassab, 1969; Maassab et $a l$, 1978; Spring et al., 1977b; Davenport et al., 1977). Attenuation, ca, and ts properties can be transferred into recombinant viruses by gene reassortment between a wild-type and the cold variant virus. A/ Ann Arbor $/ 6 / 60$ cold variant virus, therefore, is used as a donor virus for candidate live influenza vaccines lines. Studies using ferrets, hamsters, and human volunteers have demonstrated that the ca recombinant viruses are antigenic, attenuated, and genetically stable if the six nonglycoprotein genes are derived from the A/ Ann Arbor/6/60 cold variant (Murphy et $a l ., 1979,1980 a$, b; Moritz et al. 1980). However the particular gene(s) of the cold variant A/Ann Arbor/6/60 virus which function(s) to confer attenuation, ca and ts properties have not been unequivocably identified.
Initial efforts to relate the ca and ts properties of the cold variant A/Ann Arbor $/ 6 / 60$ virus to specific genes have led to limited success, primarily because the recombinants available for examination all had multiple genes from the $A / A n n$ Arbor $/ 6 / 60$ virus parent and a limited diversity in their overall gene constellations of cold-adapted and wild-type derived genes. In recombinants formed in PCK cells at $25^{\circ}$, clones which possessed both the ca and ts phenotypes always contained two polymerase genes (RNA1 and RNA3) and the NP gene of the ca A/Ann Arbor/ 6/60 parent virus (Cox et al., 1979). Derivation of the other genes varied without seemingly affecting the ca and ts phenotype. Further studies with recombinants produced at 34 or $38^{\circ}$ suggested that no single gene of $\mathrm{A} / \mathrm{Ann}$ Arbor/6/60 virus conferred the ts property, but that RNA1 and RNA7 were required from the ca A/ Ann Arbor $/ 6 / 60$ virus for expression of the ts phenotype in recombinants formed between the wt A/Ann Arbor/6/60 and ca A/Ann Arbor/6/60 viruses (Cox et al., 1981b). However, a recombinant made with A/Alaska/6/77 virus, AA-CR 31 C13 (Cox et al., 1979) contained the RNA7 of A/Alaska/6/77 virus and was still ts. The lack of single-gene recombinants, presence or absence of other cold variant-derived genes, and the use of different wild-type parents have made it difficult to assign with certainty specific cold-adapted or temperature-sensitive functions to any one particular gene of the cold variant $\mathrm{A}$ / Ann Arbor $/ 6 / 60$ virus.

This paper describes recombinant viruses isolated from mixed infections using the cold variant A/Ann Arbor/6/60 (H2N2) virus and the wild-type A/Alaska/ 6/77 (H3N2) virus. By using the permissive temperature of $33^{\circ}$ and a different host cell system, Madin-Darby canine kidney (MDCK) for recombination, single-, and limited-gene recombinants have been produced which can be used to link specific biological traits to the presence of specific A/Ann Arbor $/ 6 / 60$ genes. Eight recombinants were separated into two phenotypic groups of ca and ts, and ca and non- 
ts. This paper determines the gene constellation of each isolate, and relates specific genes with specific phenotypic traits.

\section{MATERIALS AND METHODS}

Viruses and tissue culture. The coldadapted parent was 7PI-A/Ann Arbor/6/ 60 virus (Maassab, 1969) and the wild-type parent was $A / A l a s k a / 6 / 77$ (H3N2) virus. Before recombination, the parent viruses were cloned in MDCK cells (six times at $25^{\circ}$ for the cold-variant virus and once at $39^{\circ}$ for the wild-type virus). MDCK cells (Flow Laboratory, Rockville, Md.) were used between the 62 and 72 passage level. The cell cultures were maintained in Eagle's MEM containing $10 \%$ heat-inactivated fetal calf serum, and used for making viral recombinants and for the preparation of $\left[{ }^{35} \mathrm{~S}\right]$ methionine-labeled virus-specific proteins isolated as cytoplasmic extracts. PCK cell cultures were used for the preparation of $\left[{ }^{3} \mathrm{H}\right]$ uridine-labeled viral RNA. The PCK cells (prepared as described by Maassab, 1969) were grown in 199 medium, $\mathrm{pH} \mathrm{6.8,} \mathrm{containing} 2000$ units $/ \mathrm{ml}$ penicillin, $0.4 \mathrm{mg} / \mathrm{ml}$ streptomycin, and $10 \%$ heat-inactivated fetal calf serum. The cell cultures were fed by a complete change of the growth medium on the third day after plating and infected with virus on the fifth day.

Production of recombinants. For the production of recombinants between A/Ann Arbor $/ 6 / 60$ virus and $A / A$ laska/6/77 virus, 12 individual culture tubes of $\mathrm{MDCK}$ cells were infected with $0.3 \mathrm{ml}$ of a mixture of both parent viruses each at a multiplicity of infection (m.o.i.) ranging from 5 to 10 plaque-forming units (PFU) per cell. The virus was allowed to absorb for $90 \mathrm{~min}$ at room temperature, the inoculum was removed, and $1 \mathrm{ml}$ of double-strength Eagle's basal medium ( $2 \times$ Eagle's), without serum, containing $5 \mu \mathrm{g} / \mathrm{ml}$ of TPCK trypsin was added into each tube. The infected cells were incubated at $25^{\circ}$ for 5 days or at $33^{\circ}$ for 3 days postinfection until cell lysis was evident. The progeny viruses were further passed undiluted two times in the presence of ferret antiserum (hemagglutination-inhibition titer-HI = 1:96) made against A/Ann Arbor/6/60 cold variant virus. The ca recombinants derived at 33 and $25^{\circ}$ were designated as TA-CR1 and TA-CR2, respectively. The recombinant viruses were plaque-purified three times in MDCK cells by plaque to plaque passages at $25^{\circ}$ for TA-CR2, and $33^{\circ}$ for TA-CR 1 . The triple plaque-purified viruses were then inoculated into 11-dayold embryonated eggs and incubated at $33^{\circ}$ for $72 \mathrm{hr}$. The egg pools were stored at $-70^{\circ}$.

Plaque assay. Plaque assays were performed in MDCK cells by a procedure similar to that described by Appelyard and Maber (1974). Confluent MDCK monolayers in $25-\mathrm{cm}^{2}$ plastic bottles were infected with $1.0 \mathrm{ml}$ of virus dilution in $2 \times$ Eagle's medium containing $5 \mu \mathrm{g} / \mathrm{ml}$ of TPCK trypsin. Virus was absorbed for $1 \mathrm{hr}$ at room temperature with continuous, gentle shaking, at which time the virus inoculum was aspirated off, and $4 \mathrm{ml}$ of overlay media consisting of medium $199,1.0 \%$ agarose, and $5 \mu \mathrm{g} / \mathrm{ml}$ TPCK trypsin was added. After incubation for $48 \mathrm{hr}$ at 33 and $39^{\circ}$, or for 5 days at $25^{\circ}$, plaques were stained by adding $4 \mathrm{ml}$ of $1.0 \%$ agarose in medium 199 containing $0.007 \%$ neutral red and 5 $\mu \mathrm{g} / \mathrm{ml}$ TPCK trypsin. The plaques were counted everyday for 6 days postinfection for the cultures incubated at 33 and $39^{\circ}$, or for 12 days for the cultures incubated at $25^{\circ}$.

Antigenic analysis. The subtype of the hemagglutinin (HA) antigen of the triple plaque-purified clones was determined by the hemagglutination inhibition (HI) test using A/Texas/7/77 (H3)-equine/Prague/ $1 / 56$ (N eq 1) and 7PI-A/Ann Arbor/6/60 (H2N2) antisera as reference antisera produced in chickens and in ferrets, respectively. The neuraminidase (NA) was determined by neuraminidase inhibition (NI) test using ferret immune sera to $\mathrm{A}$ / Alaska/6/77 (N2 77 and 7PI-A/Ann Arbor $/ 6 / 60(\mathrm{~N} 260)$ viruses. The procedure employed the CDC protocol for the antigenic analysis (Palmer et al., 1975).

$\left[5-, 6-^{3} H\right]$ uridine-labeled RNA. $\left[{ }^{3} \mathrm{H}\right] \mathrm{Uri}-$ dine-labeled viral RNA was prepared from 
ca recombinants and their parent viruses grown in PCK cells. Confluent PCK cells in a $150-\mathrm{cm}^{2}$ flask were infected with virus at a multiplicity of approximately 50 PFU/ cell. The virus was allowed to absorb to the cells for $1 \mathrm{~h}$ at $33^{\circ}$. The inoculum was replaced with $10 \mathrm{ml}$ of $2 \times$ Eagle's medium containing $100 \mu \mathrm{Ci} / \mathrm{ml}$ of $\left[{ }^{3} \mathrm{H}\right]$ uridine for $6 \mathrm{hr}$ at $33^{\circ}$. [5-,6- $\left.{ }^{3} \mathrm{H}\right]$ Uridine was obtained from the New England Nuclear Corporation, Boston, Mass. at approximately 37 $\mathrm{Ci} / \mathrm{mmol}$. After $6 \mathrm{hr}$ at $33^{\circ}, 20 \mathrm{ml}$ of fresh $2 \times$ Eagle's medium was added and the cell cultures incubated for $40 \mathrm{hr}$ at $33^{\circ}$. The labeled virus was harvested from the culture medium and clarified by centrifugation at $2000 \mathrm{rpm}$ for $20 \mathrm{~min}$ at $4^{\circ}$. The virus was pelleted through a $30 \%$ sucrose cushion in STE buffer (0.01 M Tris- $\mathrm{HCl}, 0.001 M$ EDTA, $0.1 M \mathrm{NaCl}$, pH 7.4) by centrifugation at 22,500 rpm for 150 min in a Beckman type 30 rotor and then resuspended in $0.4 \mathrm{ml}$ of STE buffer. The viral RNA was phenol-chloroform extracted as described previously (DeBorde and Leibowitz, 1976), ethanol precipitated, resuspended in deionized $\mathrm{H}_{2} \mathrm{O}$, and stored under liquid $\mathrm{N}_{2}$.

${ }^{35}$ S]Methionine-labeled polypeptides. Confluent MDCK monolayers grown in 16$\mathrm{mm}$ petri dishes were infected with viruses at a multiplicity of approximately $100 \mathrm{PFU} /$ cell for $1 \mathrm{hr}$ at $33^{\circ}$. The inoculum was then replaced with $0.5 \mathrm{ml}$ of Eagle's MEM deficient in methionine and incubated for $8 \mathrm{hr}$ at $33^{\circ}$. To decrease the initiation of cellular protein synthesis, the infected cells were treated with $150 \mathrm{~m} M \mathrm{NaCl}$ for $15 \mathrm{~min}$ at $33^{\circ}$ before the addition of radioactive label as described by Lamb et al. (1978). The medium was then replaced with MEM deficient in unlabeled methionine and containing 20 $\mu \mathrm{Ci} / \mathrm{ml}\left[{ }^{35} \mathrm{~S}\right]$ methionine. L-[ $\left.{ }^{35} \mathrm{~S}\right] \mathrm{Methionine}$, was obtained from Amersham, Arlington Heights, Ill. After a 2-hr incubation at $33^{\circ}$ the medium was removed and the cells lysed in $150 \mu \mathrm{l}$ of lysis buffer (Peluso et al., 1977). Lysates were scraped from the dish, sonicated, and frozen at $-20^{\circ}$.

Polyacrylamide gel electrophoresis (PAGE).Gene constellations of the recom- binant viruses were determined by differential RNA migration on mixed polyacrylamide-agarose gels. Gels consisting of $3.0 \%$ acrylamide, $0.15 \%$ bisacrylamide, $0.6 \%$ agarose, and $0.1 \%$ SDS in $1 \times$ TBE buffer $(0.089 M$ Tris-base, 0.089 $M$ boric acid, and $2.76 \mathrm{~m} M$ EDTA) described by Peacock and Dingman (1968) were cast between two glass plates (13 $\times 7.5 \times 3 / 16$ in) separated by $1.5-\mathrm{mm}$ acrylic spacers. Polymerization of the gels was performed at $40^{\circ}$, catalyzed by adding $250 \mu \mathrm{l}$ of $10 \%$ ammonium persulfate and $25 \mu \mathrm{l}$ of $N, N^{\prime}, N^{\prime}$-tetramethylenediamide (TEMED) for every $100 \mathrm{ml}$ of gel solution. Standard concentrations of catalysts at the elevated temperatures caused too rapid and uneven polymerization of the gels. After the acrylamide polymerized, the gels were placed at room temperature overnight to ensure complete polymerization of both components. A stacking gel containing the loading wells was formed on top of the running gel $4 \mathrm{hr}$ prior to use. It had the same polyacrylamide concentration as the running gel, but it lacked agarose, and contained only $1 / 5 \times$ TBE buffer. The gels were warmed to the appropriate running temperature by a water jacket on the inner side of the gel during the polymerization of the stacking gel. Purified $\left[{ }^{3} \mathrm{H}\right.$ ]viral RNA in deionized $\mathrm{H}_{2} \mathrm{O}$ was mixed $1: 1 \mathrm{v} / \mathrm{v}$ with $2 \times$ loading buffer ( $20 \%$ sucrose, $1 / 5 \times$ TBE, $0.2 \%$ SDS) and heated at $56^{\circ}$ for $2 \mathrm{~min}$. The samples were loaded and electrophoresed for $24 \mathrm{hr}$ at $37^{\circ}$ or for $18 \mathrm{hr}$ at $30^{\circ}$ both at $250 \mathrm{~V}$ (constant voltage) using a running buffer of $1 \times$ TBE buffer with $0.1 \%$ SDS. The gels were dried and fluorgraphed (Laskey and Mills, 1975) using preflashed X-ray film.

Virus polypeptides were analyzed by high-resolution discontinuous PAGE using Tris-glycine buffer and SDS (Laemmli, 1970). In the present study $13 \%$ acrylamide gels containing an acrylamide/ bisacrylamide ratio of 28:0.4 in $0.375 \mathrm{M}$ Tris-HCl (pH 8.8) with $0.1 \%$ SDS were used for resolution of the $\mathrm{M}$ proteins. Stacking gels were $3.0 \%$ acrylamide, $0.08 \%$ bisacrylamide, and $0.1 \%$ SDS in 0.125 $M$ Tris- $\mathrm{HCl}$ (pH 6.8). Samples were pre- 
pared in electrophoresis sample buffer (Laemmli, 1970) and heated to $100^{\circ}$ for 2 min. Electrophoresis was performed for $5 \mathrm{hr}$ at a constant voltage of $120 \mathrm{~V}$ and the gels were then fixed in $10 \%$ trichloroacetic acid, $30 \%$ methanol, and $10 \%$ acetic acid. Fluorographs were prepared as described above.

\section{RESULTS}

\section{Phenotypic Analysis of the Recombinant Viruses}

Cold-adapted (ca) recombinants were produced in MDCK cells between ca A/ Ann Arbor $/ 6 / 60$ cold-variant virus and A/ Alaska/6/77 virus, a recent epidemic strain. In this study two different temperatures were employed for recombination: $33^{\circ}$, a permissive temperature for both parental strains, and $25^{\circ}$, a permis- sive temperature for the donor virus but a restrictive temperature for the wild-type virus. These conditions were used to determine whether or not the recombinant viruses would possess different phenotypic and genetic properties depending upon the incubation temperature. Five clones from each temperature were randomly selected and examined by plaque assays at 25,33 , and $39^{\circ}$ in MDCK cells. The results are shown in Table 1. Two TA-CR1 clones $\left(\mathrm{T}_{1}\right.$ 3-5-1 and $T_{5} 36-1-1$ ) were shown to be nonca and non-ts. The efficiency of plating (EOP) of these two clones was at least 1000-fold less at $25^{\circ}$ than at $33^{\circ}$, and showed no decrease at 39 compared to $33^{\circ}$. Upon genetic analysis these clones were shown to contain all wild-type genes, and thus were not recombinants, but reisolates of the wild-type parent. Two other clones, $\mathrm{T}_{6}$ 6-1-1 and $\mathrm{T}_{6}$ 6-2-1 were ca and ts. The

TABLE 1

Plaqijing Gfficiency of Recombinants Derived at $33^{\circ}$ (TA-CR1) and at $25^{\circ}$ (TA-CR2)

\begin{tabular}{|c|c|c|c|}
\hline \multirow[b]{2}{*}{ Clones } & \multicolumn{2}{|c|}{$\begin{array}{l}\text { Log } 10 \text { reduction of plaque } \\
\text { titer at indicated } \\
\text { temperature from that } \\
\text { observed at permissive } \\
\text { temperature }\left(33^{\circ} \mathrm{C}\right)\end{array}$} & \multirow{2}{*}{$\begin{array}{c}\text { Biological } \\
\text { properties }^{a}\end{array}$} \\
\hline & $25^{\circ}$ & $39^{\circ}$ & \\
\hline \multicolumn{4}{|l|}{ TA-CR1 } \\
\hline $\mathrm{T}_{1}$ 3-5-1 & 3.0 & -0.04 & Non-ca and non-ts \\
\hline $\mathrm{T}_{4}$ 31-1-1 & 0.9 & -0.04 & ca and non-ts \\
\hline $\mathrm{T}_{5} 36-1-1$ & 5.0 & -0.04 & Non-ca and non-ts \\
\hline $\mathrm{T}_{6} 6-1-1$ & 0.3 & 6.0 & ca and ts \\
\hline$T_{6} 6-2-1$ & 0.3 & 6.0 & ca and ts \\
\hline \multicolumn{4}{|l|}{ TA-CR2 } \\
\hline $\mathrm{T}_{2} 36-3-1$ & 0.8 & 0.2 & ca and non-ts \\
\hline $\mathrm{T}_{2} 36-3-2$ & 0.9 & 0.4 & ca and non-ts \\
\hline $\mathrm{T}_{3} 25-1-1$ & 0.4 & -0.2 & ca and non-ts \\
\hline$T_{4} 8-7-1-1$ & 0.6 & 0 & ca and non-ts \\
\hline $\mathrm{T}_{5} 31-4-2$ & 0.3 & 1.0 & ca and non-ts ${ }^{b}$ \\
\hline \multicolumn{4}{|l|}{ Parent strains } \\
\hline A/Ann Arbor $/ 6 / 60$ & 0.4 & 6.0 & ca and ts \\
\hline A/Alaska/6/77 & 4.0 & -0.2 & Non-ca and non-ts \\
\hline
\end{tabular}

\footnotetext{
" ca indicates substantial growth at $25^{\circ}$; non-ca indicates little or no growth at $25^{\circ}$; ts indicates little or no growth at $39^{\circ}$; non-ts indicates substantial growth at $39^{\circ}$.

${ }^{b}$ Tiny plaques appeared at $39^{\circ}$, but the size did not increase and also did not grow in eggs.
} 
plaquing efficiency for each was similar at 25 and $33^{\circ}$, but with a $6 \log$ drop in titer at $39^{\circ}$. The final TA-CR1 clone $\mathrm{T}_{4}$ 31-1-1 and all of the TA-CR2 clones were ca and non-ts, since they plaqued equally well at all three temperatures. These data indicate that in MDCK cells: (1) the two in vitro markers of $A / A n n$ Arbor/6/60 virus can be transferred not only at suboptimal temperature, but also at permissive tem- perature, as found in PCK cells (Maassab et $a l ., 1978)$ and (2) the ca phenotype can reassort independently of the ts phenotype.

\section{Efficiency of the Cold Adaptation of the Recombinants}

The degree of cold adaptibility (DOCA) of the ca recombinants was calculated by the following equation:

$$
\mathrm{DOCA}=\frac{\operatorname{EOP} 25^{\circ} / 33^{\circ} \text { of recombinant virus }}{\operatorname{EOP} 25^{\circ} / 33^{\circ} \text { of A/Ann Arbor } / 6 / 60 \text { virus }} \times 100(\%)
$$

The DOCA values together with the antigenic subtypes of the recombinants (as determined by the $\mathrm{HI}$ and NI tests described under Materials and Methods) are presented as part of Table 2 . The values given for the DOCA are averages of at least three experiments and the values for each recombinant varied within itself by no more than $\pm 6 \%$. The data show that all recombinants have the $A /$ Alaska/6/77 $\mathrm{HA}$, and five out of the eight recombinants possessed the A/Ann Arbor/6/60 NA. If the recombinants are ranked by descending values of the DOCA it becomes apparent that those values at the top of the scale have the NA gene of the A/Ann Arbor $/ 6 / 60$ virus while the bottom three recombinants have the NA gene of the $\mathrm{A} /$ Alaska/6/77 virus. These results show that the NA gene of A/Ann Arbor/60 virus covaries with enhanced cold adaptation when present in ca recombinant viruses. This relationship will be discussed further after the section on genotyping, below.

\section{"Genotype" Characterization of Recombi- nant Viruses}

The parental derivation of each recombinant's eight RNA genes has been determined "genotyped" by a combination of protein and RNA PAGE. Using two different temperatures, 30 and $37^{\circ}$, for RNA PAGE, migrational differences in all eight RNA segments between both A/Ann Arbor/6/60 and $A / A l a s k a / 6 / 77$ parental vi- ruses could be observed. RNA7, ${ }^{3}$ the $M$ protein gene, can be analyzed if the gel is overexposed. This RNA band is generally diffuse and difficult to observe. Therefore, the parental derivation of the $M$ gene was also determined using protein PAGE.

Previous genetic analyses of other ca recombinant viruses have been performed by Drs. N. J. Cox and A. P. Kendal (in collaboration with the senior author, H. F. M., of this publication) at the Centers for Disease Control, Atlanta, Georgia using a similar electrophoretic system, but with a different buffer. They have made specific gene-protein assignments for the HA, NA, NP, M, and NS genes of A/Ann Arbor $/ 6 / 60$ virus using their defined conditions (Kendal et al., 1977; Cox and Kendal, 1978). Funetional gene assignments for the polymerase genes related RNAs 1 and 3 of A/Ann Arbor/6/60 virus to the fowl plaque virus (FPV) polymerase 3 gene and FPV polymerase 2 gene, respectively. Thus RNA 2 of A/Ann Arbor/6/60 virus was functionally related to FPV polymerase 1 gene (Cox et al., 1981a).

Analysis in this laboratory of ca recom-

\footnotetext{
${ }^{3}$ The RNA segments are identified by a number which gives its migrational position among the other RNA segments reading from the origin of the polyacrylamide gel. RNAs 1, 2, and 3 refer to the largest RNA segments as separated at $37^{\circ}$ as under Materials and Methods. RNAs 4-8 refer to the five smaller RNA segments as separated at $30^{\circ}$ as under Materials and Methods.
} 
TABLE 2

Gene Constellations and Summary of Biological Properties of ca Recombinants

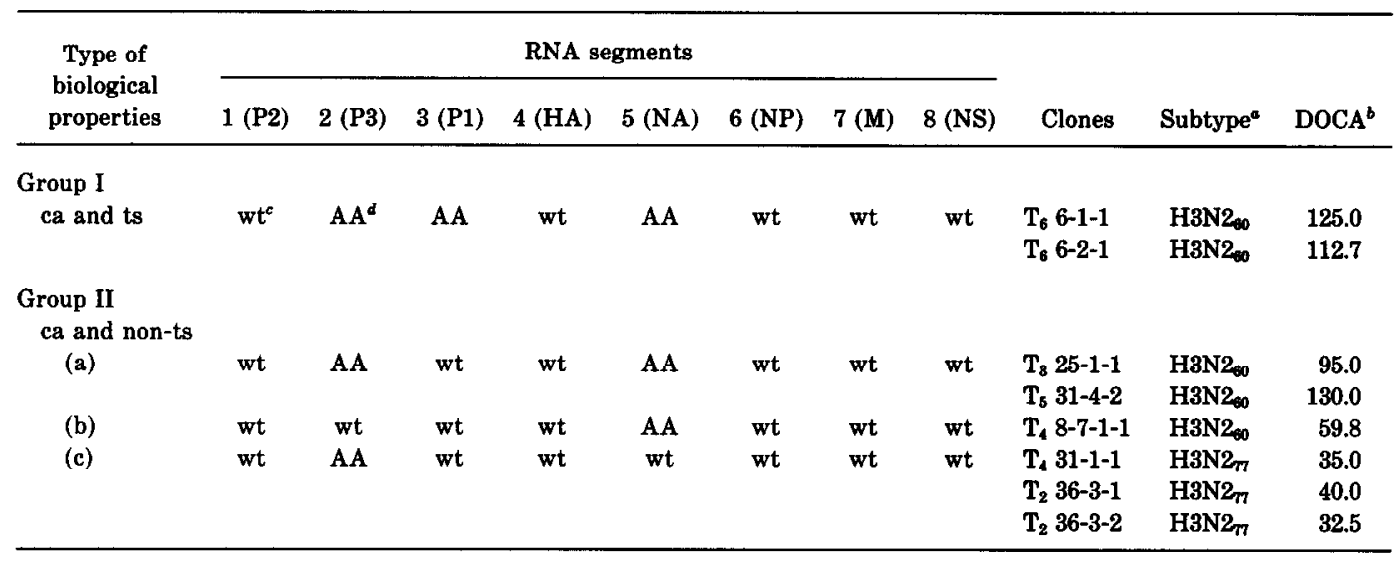

- Determined as under Materials and Methods.

${ }^{6}$ Calculated as described in text.

' $w \mathrm{t}=$ RNA derived from $\mathrm{A} /$ Alaska/6/77.

$\therefore$ AA $=$ RNA derived from A/Ann Arbor $/ 6 / 60$.

binants previously genotyped by Drs. Cox and Kendal has shown that the migration pattern of A/Ann Arbor/6/60 RNA segments using the electrophoresis conditions given under Materials and Methods varies from theirs by the inversion of two pairs of RNA segments (data not shown). At $37^{\circ}$, RNA2 and RNA3 represent RNAs 3 and 2 , respectively, and at $30^{\circ}$, RNA5 and RNA6 represent RNAs 6 and 5, respectively, as defined by Cox et al, (1979, 1981b). Thus, in this paper RNA migration relates to gene assignments as follows: (at $37^{\circ}$ ) RNA1 = "FPV $P_{3}$," RNA $2=$ "FPV $\mathrm{P}_{2}$," and RNA3 = "FPV P "; (at 30 $0^{\circ}$ ) RNA4 $=\mathrm{HA}, \mathrm{RNA} 5=\mathrm{NA}, \mathrm{RNA6}=\mathrm{NP}, \mathrm{RNA} 7$ $=\mathrm{M}$, and RNA8 = NS.

Figure 1 shows the RNA migration for both parent viruses and five representative recombinants after electrophoresis at $30^{\circ}$. RNAs $1-3$ are not clearly defined at this temperature, but differences between the remaining RNA segments can be seen. For example, lane 4, clone $\mathrm{T}_{3}$ 25-1-1 derives RNAs 4, 6, 7, and 8 from the A/Alaska 6/ 77 parent and RNA5 from A/Ann Arbor/ 6/60 parent. It can be noted that functionally, A/Ann Arbor/6/60 RNA5 must correspond to A/Alaska/6/77 RNA5 and not to $A / A l a s k a / 6 / 77$ RNA6, because if the latter were true, a single band at the RNA5 and 6 position as seen for $\mathrm{T}_{3} 25-1$ 1 would not be possible for a viable recombinant virus.

The parental origin of the $M$ gene was also determined using protein PAGE as seen in Fig. 2. It is clear from these data that not only the M, but NS, and HA proteins in all the recombinants resemble the corresponding A/Alaska/ $6 / 77$ proteins and not those of the A/Ann Arbor/ 6/60 virus. The RNA data from Fig. 1, for the $\mathrm{HA}$ and NS genes, RNA4 and RNA8, respectively, agree with the protein data, that all recombinants derive these genes from the wild-type, A/Alaska/6/77 parent.

Figure 3, RNA PAGE at $37^{\circ}$, distinctly separates the three polymerase genes. Thus, recombinants $T_{5}, 36-1-1$ and $T_{4}$ 8-71-1 have all three A/Alaska/6/77 polymerase genes; recombinant $\mathrm{T} 4$ 31-1-1 has RNAs 1 and 3 from the A/Alaska/6/77 virus and RNA2 from the A/Ann Arbor/ $6 / 60$ virus; and recombinant $\mathrm{T}_{6} 6-1-1$ has A/Alaska/6/77 RNA1 and A/Ann Arbor/ 6/60 RNA2 and 3. These four recombinants showed the total range of variation among all the recombinants in the three polymerase genes.

Table 2 presents a summary of the ge- 


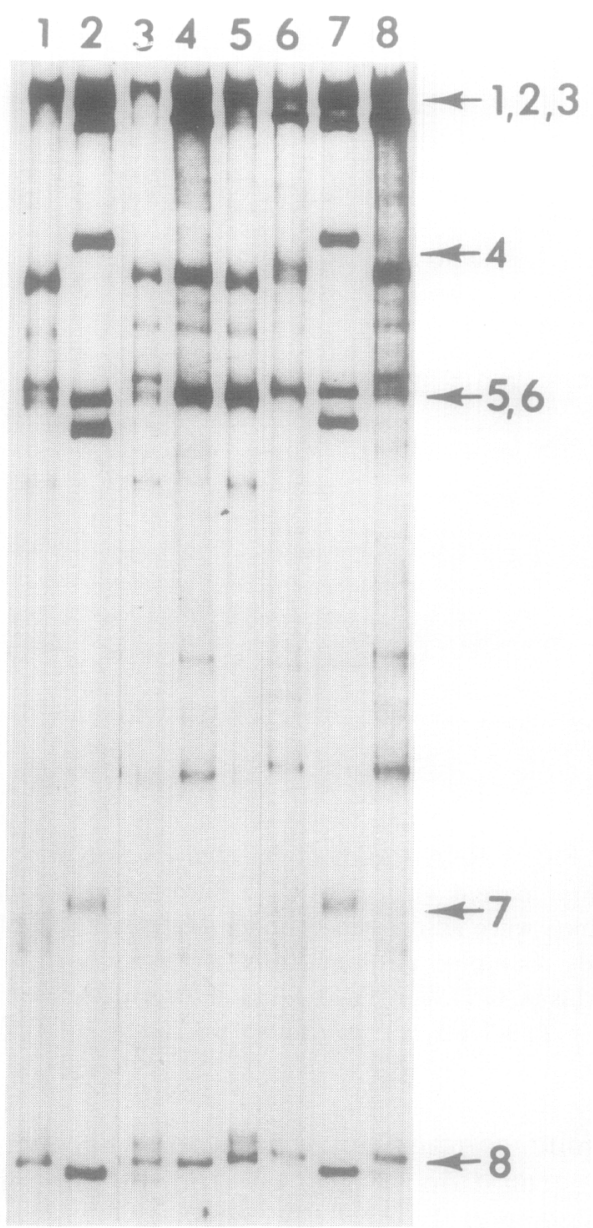

FIG. 1. RNA PAGE of selected recombinants and their parent viruses at $30^{\circ}$. Electrophoresis conditions were as described under Materials and Methods. Samples on lanes are: $1=\mathrm{A} /$ Alaska $/ 6 / 77,2$ $=A / A n n$ Arbor $/ 6 / 60,3=T_{5} 36-1-1,4=T_{3}$ 25-1-1, $5=T_{4}$ 8-7-1-1, $6=T_{6} 6-1-1,7=A /$ Ann Arbor $/ 6 / 60$, $8=T_{4} 31-1-1$. (It should be noted that at $30^{\circ}$, the actual order of A/Ann Arbor/6/60 RNAs 1-3 as defined at $37^{\circ}$ is RNA1 and 3 followed by RNA2.)

notype data derived from Figs. 1-3 together with the biological ca and ts marker data from Table 1 and the DOCA values. The biological data originally classified the recombinants into two groups; Group $\mathrm{I}=\mathrm{ca}$ and ts and Group II = ca and nonts. Group II, ca and non-ts contained recombinants of three different gene constellations: (IIa) has two A/Ann Arbor/6/
60 genes, RNA2 and RNA5 (NA), and the other six genes are from A/Alaska/6/77 virus: (IIb) has only one A/Ann Arbor/6/ 60 gene, RNA5(NA); and (IIc) also has only one A/Ann Arbor/6/60 gene, RNA2. Group $I$, ca and ts recombinants, all contained three A/Ann Arbor/6/60 genes RNA2, RNA3, and RNA5(NA). Thus, both RNA2 and RNA5 could individually enable growth at $25^{\circ}$ for single-gene recombinants. Furthermore, a change in gene constellation from Group IIa to Group I (an addition of just one A/Ann Arbor/6/60 gene-RNA3) caused a change in phenotype from non-ts to ts.

\section{Virus Growth Patterns at $25^{\circ}$}

Growth curves of the parents and all eight recombinant viruses were analyzed

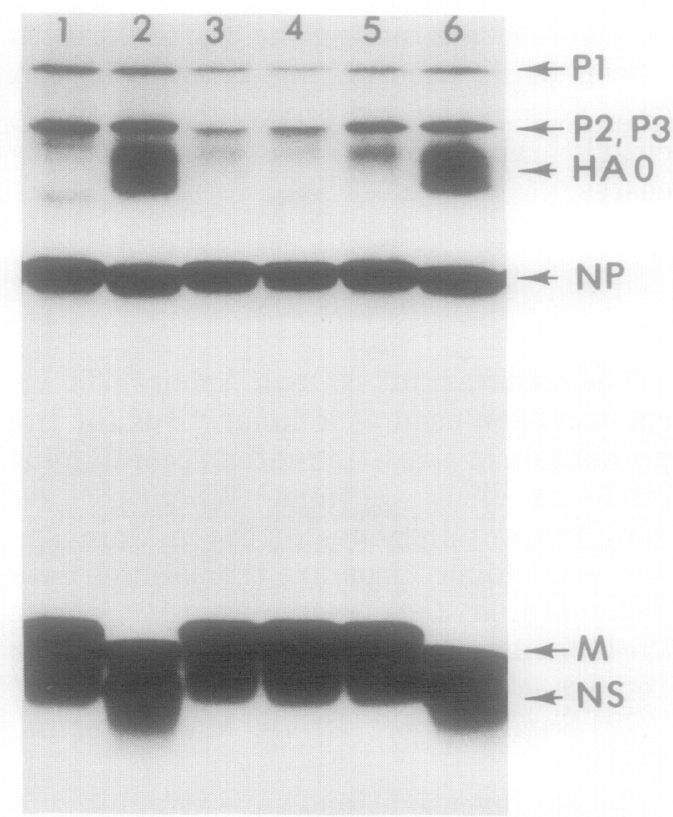

FIG. 2. Protein PAGE of selected recombinants and their parent viruses. Electrophoresis conditions were as described under Materials and Methods for a 13\% polyacrylamide separation gel. Samples on lanes are: $1=\mathrm{T}_{4}$ 31-1-1, $2=\mathrm{A} /$ Ann Arbor $/ 6 / 60,3=\mathrm{A} /$ Alaska $/$ $6 / 77,4=\mathrm{T}_{4} 8-7-1-1,5=\mathrm{T}_{6} 6-1-1$, and $6=\mathrm{A} /$ Ann Arbor $/ 6 / 60$. Samples were from MDCK cell lysates, electrophoresed without $\beta$-mercaptoethanol in the loading buffer. 
at $25^{\circ}$. MDCK cells were infected using an m.o.i. of $10 \mathrm{PFU} /$ cell. Aliquot samples were taken every $24 \mathrm{hr}$ up to 6 days postinfection. The samples were titrated by plaque assay at $33^{\circ}$. Figure 4 shows the extent of variation present in the growth curves of four clones representative of the four different gene constellations present in the eight recombinant viruses. Three types of growth curves are readily apparent: fast growth rate early in infection and high virus yield (Figs. $4 \mathrm{~A}$ and $\mathrm{B}-$ gene constellations I and IIa); fast growth rate early in infection and intermediate virus yield (Fig. $4 \mathrm{C}$-gene constellation IIc); and slow growth rate early in infection and high virus yield (Fig. 4D-gene constellation IIb). Thus it appears that the two single-gene recombinants IIb and IIc confer the cold-adaptive property by different mechanisms: the single-gene recombinant containing A/Ann Arbor/6/60 RNA 2 polymerase gene acting early in the growth curve, while the A/Ann Arbor/6/60 NA gene acts at the end of the growth curve, clearly representing two different processes.

\section{DISCUSSION}

The cold-variant A/Ann Arbor/6/60 virus has been used as a donor virus for the production of live attenuated recombinant influenza virus vaccines. When the six nonglycoprotein genes of the A/Ann Arbor $/ 6 / 60$ donor virus are transferred into cold-adapted (ca) recombinant viruses, these viruses are attenuated for humans and are genetically stable. (Murphy et al., 1979; Spring et al., 1977b; Massab et al., 1981).

Recent investigations have attempted to identify which A/Ann Arbor/6/60 gene(s) confer cold adaptation, temperature sensitivity, and attenuation (Maassab et al, 1977; Kendal et al., 1977, 1978; Reeve et al., 1980; Murphy et al., 1981). Such efforts so far have been only partially successful. One difficulty has been that the ca recombinant viruses produced in the PCK cells at $25^{\circ}$ possessed a limited variation in

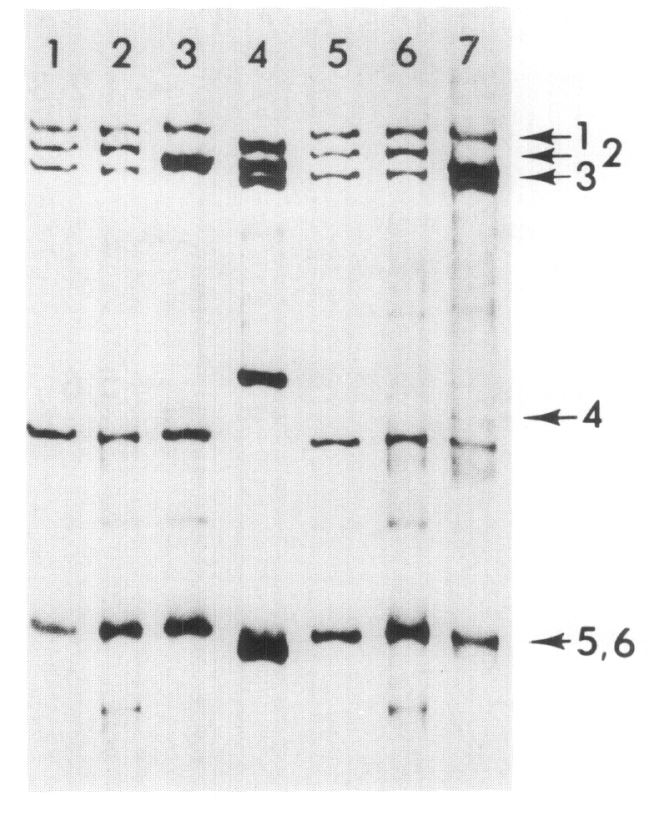

FIG. 3. RNA PAGE of selected recombinants and their parent viruses at $37^{\circ}$. Electrophoresis conditions were as described under Materials and Methods. Samples on lanes are: $1=\mathrm{T}_{5} 36-1-1,2=\mathrm{A} /$ Alaska/6/77, $3=\mathrm{T}_{4}$ 31-1-1, $4=\mathrm{A} / \mathrm{Ann}$ Arbor $/ 6 / 60$, $5=\mathrm{T}_{4}$ 8-7-1-1, $6=\mathrm{A} /$ Alaska $/ 6 / 77$, and $7=\mathrm{T}_{6} 6-1-1$.

gene compositions and only rarely was segregation of the ca and ts phenotype observed. In addition, recombinants with the same gene constellations, but a different wild-type parent virus, may show variations in their biological properties because each gene does not act independently but in concert with at least some of the other genes. This study has been limited to evaluation of recombinants derived in MDCK cells using A/Ann Arbor/ $6 / 60$ cold variant and $A / A l a s k a / 6 / 77$ wild-type viruses. The $33^{\circ}$ incubation temperature (a permissive temperature for both parents) and a new host system, MDCK cells, were used in an effort to generate a wider variety of gene constellation and avoid selective advantage for either ca or ts $^{+}$ property. Due to selective pressure the recombinants made at $25^{\circ}$ could contain new cold-adapted mutations on the wild-type genes and thus findings with these recombinants may be ambiguous. However, in 

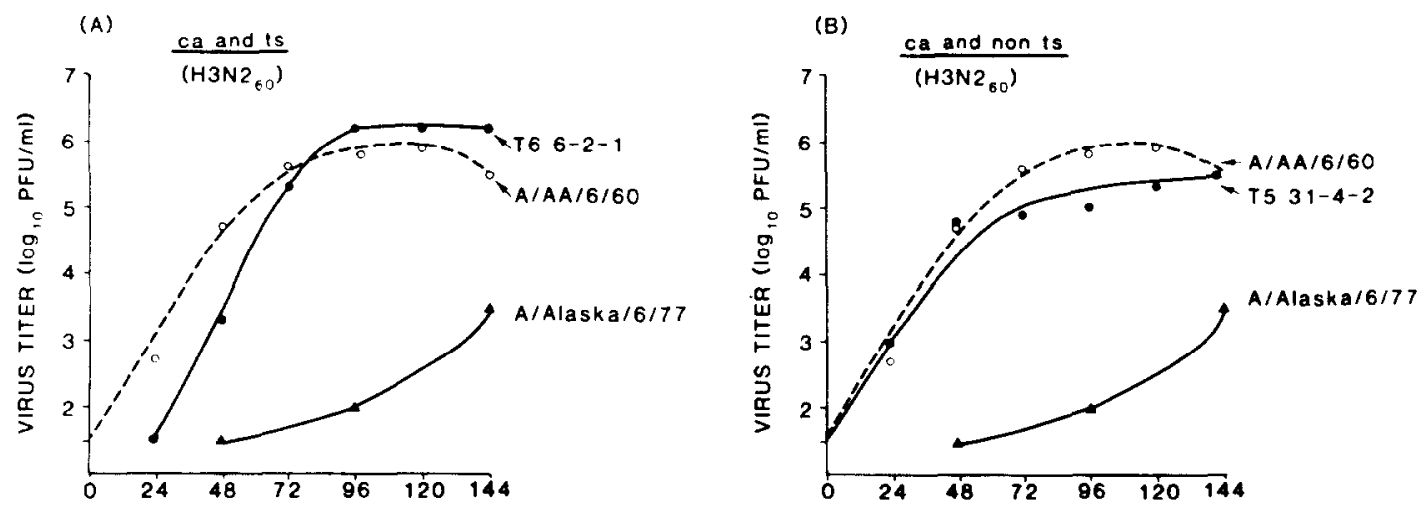

(C)

HOURS AFTER INFECTION
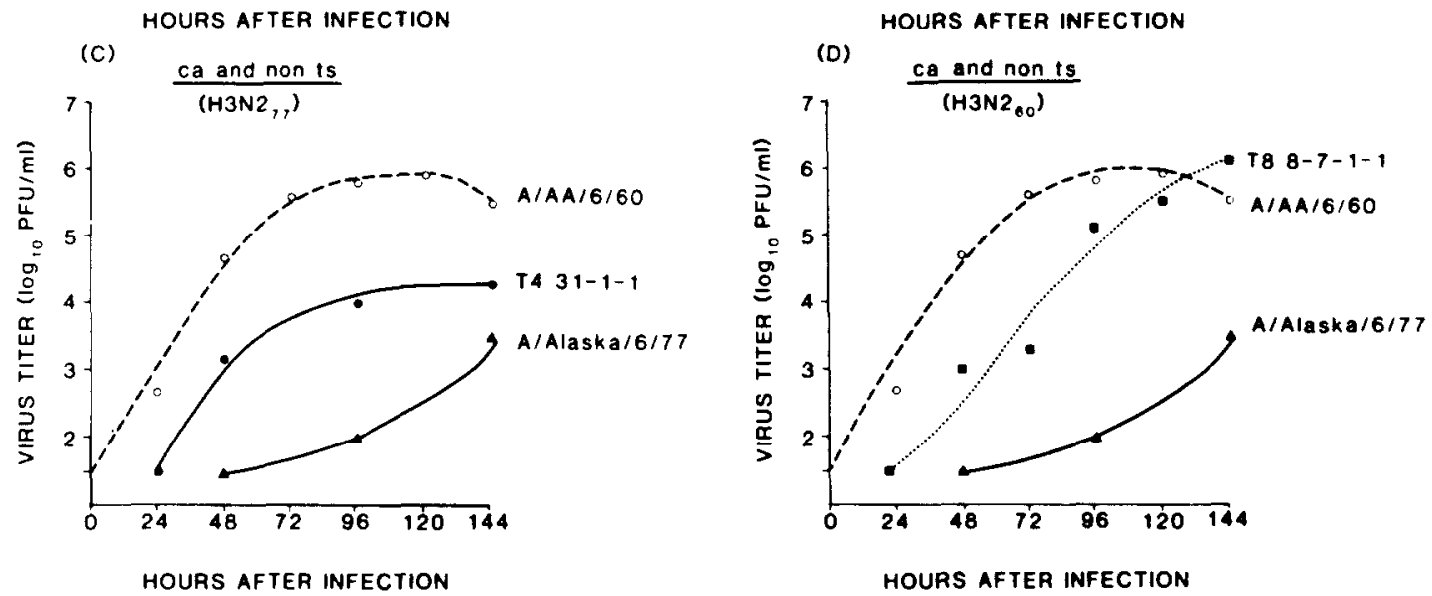

FIG. 4. Growth curve analysis of cold-adapted recombinants at $25^{\circ}$ in MDCK cells. Infection and sampling were performed as described under Materials and Methods. Each curve is an average of three experiments.

the context of this paper it can be noted that one genotype (IIc) has recombinants of both 25 and $33^{\circ}$ origin, and that these recombinants showed no variation in their biological behavior which would necessitate the mechanism of an unknown ca mutation on one of their wild-type genes. Further, during a backcross experiment at $39^{\circ}$ between $\mathrm{T}_{6}$ 6-6-1 (a recombinant isolated at $33^{\circ}$ ) and $\mathrm{A} /$ Alaska/6/77 wildtype parent both gene constellations IIa and IIb were derived. These recombinants behaved phenotypically identical to those derived at $25^{\circ}$ in the original experiment, again showing no evidence requiring a hidden ca mutation on the wild-type genes.

Recombinants separated into two groups based on their cold-adaptive and temper- ature-sensitive properties: Group I, ca and ts; and Group I, ca and ts; and Group II, ca and non-ts. Gene constellations of recombinant clones were determined by PAGE of viral RNA and proteins. Group I recombinants were all the same genotype deriving three A/Ann Arbor/6/60 genes RNA 2,3, and 5 from the cold-variant parent, while Group II recombinants showed three different gene constellations: (IIa) having A/Ann Arbor/6/60 RNA 2 and 5, and two single-gene recombinants; (IIb) having only A/Ann Arbor/6/60 RNA5; and (IIc) having only A/Ann Arbor $/ 6 / 60$ RNA2.

These data are the first observations in which only a single gene of A/Ann Arbor/ 6/60 virus has been transferred to a re- 
combinant and confers cold adaptability. Most ca recombinants produced in PCK cells at $25^{\circ}$ possess predominantly A/Ann Arbor $/ 6 / 60$ genes and not those of the wild-type parent, whether A/Alaska/6/77 virus or some other virus (Kendal et al., 1978; Cox et al., 1979; Murphy et al., 1980c). Thus, these single-gene recombinants can directly establish the presence or absence of cold-adaptive properties of the specific A/Ann Arbor/6/60 gene present in the recombinant.

The extent of cold adaptability of the ca recombinants examined on a basis of efficiency of plating between 25 and $33^{\circ}$ indicated that the neuraminidase (NA) gene of the A/Ann Arbor/6/60 enhances the degree of cold adaptability (Table 2). Further, the recombinants which possessed the A/Ann Arbor/6/60 NA gene grew to higher virus yield at $25^{\circ}$ than those which possessed A/Alaska/6/77 gene from wildtype virus (Fig. 4). These results suggest that the NA gene of the cold variant donor virus can function to increase the virus yield at $25^{\circ}$. The A/Ann Arbor/6/60 NA gene is not absolutely required to confer the ca property as shown by the second type of single-gene recombinants: those viruses with only RNA 2 from the A/Ann Arbor $/ 6 / 60$ virus. In addition many other recombinants made between A/Ann Arbor $/ 6 / 60$ cold variant virus and wild type viruses (A/Alaska/ 6 / 77 virus among them) lack the A/Ann Arbor/6/60 NA gene, but are also cold adapted.

Analysis of the growth pattern demonstrated that there were three types of growth curves based on the growth rate early in infection and the final virus yield (Fig. 4). The ts property did not directly affect the early growth rate or the virus yield at $25^{\circ}$. High virus yield was clearly demonstrated (by both analyses of cold adaptability and growth pattern) to be linked to the presence of the NA gene from the cold variant, however, it did not affect the early virus growth rate at $25^{\circ}$. This finding is consistent with the concept that the neuraminidase may function late in infection during maturation of the virus particle (Klenk et al, 1970), or in virus release (Webster and Laver, 1967). The three growth patterns correlated with the genotypes as follows: (IIa), RNAs 2 and 5 from A/Ann Arbor $/ 6 / 60$ had a fast growth rate early in infection and a high virus yield; (IIb), RNA5(NA) from A/Ann Arbor $/ 6 / 60$ had a slow growth rate early in infection, but a high final virus yield; and (IIc), RNA2, from A/Ann Arbor/6/60 had a fast growth rate early in infection and lower final virus yield. Thus, while both single-gene recombinants containing either RNA2 or RNA5(NA) of A/Ann Arbor $/ 6 / 60$ were cold adapted, the two $A$ / Ann Arbor/6/60 genes conferred this property through different mechanisms. From correlation with the data of Cox et al. (1981a) the gene product of RNA2 is involved in cRNA synthesis and should show its action early in infection. Thus, the presence of a cold-adapted cRNA polymerase could enhance the rate of virus production by functioning at a higher rate at $25^{\circ}$, than a nonadapted cRNA polymerase and show a higher virus yield early in the growth curve. Similarly, the presence of a cold-adapted NA protein might enhance the release of virus at $25^{\circ} \mathrm{com}-$ pared to a non-cold-adapted NA protein and have no effect on the early growth rate of the virus.

The type (IIa) gene constellation showed an additive phenotype due to the presence of both genes, but showed no enhancement of one another's effects, i.e., the final yield was similar to that of the (IIb) viruses, and the fast growth rate early in the infection appeared no sooner, nor was it much faster than in (IIc) viruses.

Group I recombinants, ca and ts, had three A/Ann Arbor/6/60 genes, RNA2 and RNA5(NA) (which by themselves or together conferred growth at $25^{\circ}$ but not temperature sensitivity in MDCK cells), and A/Ann Arbor/6/60 RNA3 which in combination did cause these recombinants to become temperature sensitive. Backcrosses using the wild-type parent and $\mathrm{T}_{6}$ 6-1-1, a Group I recombinant, did not generate any different gene constellations from the three Group II types already described in the original recombination ex- 
periments upon examination of eight backrecombinants This lack of new constellations could be due to cellular or viral controls on the recombination process, lethality of certain gene combinations, or just to chance in selecting the particular isolates for examination. Screening of more backcross isolates is in progress. All isolates of the backcross experiments had lost RNA3 of A/Ann Arbor/6/60 and were no longer temperature sensitive (data not shown). Whether a temperature-sensitive lesion is present on A/Ann Arbor/6/60 RNA3 or whether ts lesions on either A/ Ann Arbor/6/60 RNA2 and RNA5 are in a state of extragenic supression when in the presence of $\mathrm{A} / \mathrm{Alaska/6/77} \mathrm{RNA3}$ is not known. Bearing on this issue, the single-gene recombinants, (IIc) containing A/Ann Arbor/6/60 RNA2, have been found to be temperature sensitive, if plaqued in PCK cells (manuscript in preparation). The single-gene recombinants (IIb), containing A/Ann Arbor/6/60 RNA5(NA), remained ca and non-ts in PCK cells. Thus, RNA2 and, possibly, RNA3 of A/Ann Arbor $/ 6 / 60$ virus contain ts lesions which seem to be under a complex control involving either extragenic suppression, host cell controls, or both. Kendal and co-workers (1978) suggested that the ts property results when RNAs 1 and 3 (RNAs 1 and 2 of this paper) of A/Ann Arbor/6/60 are present in the recombinants. Subsequently they found that RNA1 and RNA7 (M) were required for the ts property in different ca recombinations (Cox et al., $1981 \mathrm{~b})$. As with the data of this paper, their results suggest that the ts property is polygenic and complex in expression varying with the precise gene constellation, wild-type parent and host cell system. The data in this paper demonstrate the usefulness of single-gene recombinants in unraveling polygenic and complex phenotypic markers, and the need for single-gene recombinants covering the entire range of the eight RNA segments. Once single-gene recombinants are characterized, then contributions of individual genes can be examined in more complex recombinants to study interactions between viral genes: no effect, suppression, or enhancement.

\section{ACKNOWLEDGMENTS}

We thank Curt Smitka for his expert technical assistance. This investigation was supported in part by the Kaketsuken, Kumamoto, Japan, Institute of Microbiology, Sendai, Japan; by Contract No. 80 1368-C1 of Sandoz Forschung Institut, Vienna, Austria; and by Contract No. 1-AI-72521, National Institute of Allergy and Infectious Diseases, Development and Applications Branch, Bethesda, Maryland 20205.

\section{REFERENCES}

Almond, J. W., MCGeoch, D., and BarRy, R. D. (1977). Method for assigning temperature-sensitive mutants of influenza viruses to individual segments of the genome. Virology 81, 62-73.

APPleyarD, G., and MABER, H. B. (1974). Plaque formation by influenza viruses in the presence of trypsin. J. Gen. Virol 25, 351-357.

Cox, N. J., and KENDAL, A. P. (1978). Effect of temperature on the order of electrophoretic migration of influenza virus neuraminidase and nucleoprotein genes in acrylamide gels lacking denaturing agents. J. Gen. Virol. 40, 229-232.

Cox, N. J., Kendal, A. P., MaAssab, H. F., ScholTISSEK, C, and SPRING, S. B. (1981a). Genetic synergism between matrix protein and polymerase protein required for temperature-sensitivity of the cold-adapted influenza A/Ann Arbor/6/60 mutant virus. In "The Replica of Negative Strand Viruses" (D. W. L. Bishop and R. W. Compans, eds.), pp. 405-413. Elsevier/North-Holland, New York.

CoX, N. J., KoNNECKE, I., KENDAL, A. P., and MAASSAB, H. F. (1981b). Genetic and biochemical analysis of the A/Ann Arbor/6/60 cold-adapted mutant. In "Genetic Variation among Influenza Viruses" (D. Nayak, ed.), pp. 639-652. Academic Press, New York.

Cox, N. J., MaAssab, H. F., and KendaL, A. P. (1979). Comparative studies of wild-type and cold-mutant (temperature sensitive) influenza viruses: Nonrandom reassortment of genes during preparation of live virus vaccine candidates by recombination at $25^{\circ}$ between recent $\mathrm{H} 3 \mathrm{~N} 2$ and $\mathrm{H} 1 \mathrm{~N} 1$ epidemic strains and cold-adapted A/Ann Arbor/6/60. Virology 97, 190-194.

Davenport, F. M., Hennessy, A. V., MaAssab, H. F., Minuse, E., Clark, L. C., Abrams, G. C., and Mitcheli, J. R. (1977). Pilot studies on recombinant cold-adapted live-type $A$ and $B$ influenza virus vaccines. $J$. Infect. Dis. 136, 17-25.

DeBornf, D. C., and I.eirowitz, R. D. (1976). Poly- 
adenylic acid size and position found in sindbis virus genome and in MRNA species. Virology 72, 80-88.

INGLIS, S. C., CARROL, A. R., LAMB, R. A., and MAHY, B. W. J. (1976). Polypeptides specified by the influenza virus genome. I. Evidence for eight distinct gene products specified by fowl plaque virus. Virology 74, 480-503.

Kendal, A. P., Cox, N. J., Murphy, B. R., Spring, S. B., and MAASSAB, H. F. (1977). Comparative studies of wild-type and "cold-mutant" (temperature-sensitive) influenza viruses: Genealogy of the matrix (M) and non-structural (NS) proteins in recombinant cold-adapted H3N2 viruses. J. Gen. Virol 37, 145-159.

Kendal, A. P., Cox, N. J., SpRING, S. B., and MaAsSAB, H. F. (1978). Biochemical characteristics of recombinant viruses derived at suboptimal temperatures: Evidence that ts lesions are present in RNA segments 1 and 3, and that RNA 1 codes for the virion transeriptase enzyme. In "Negative Strand Viruses and the Host Cell" (B. W. J. Mahy and R. O. Barry, eds.), pp. 733-743. Academic Press, New York.

KLENK, H. D., Compans, R. W., and Choppin, P. W. (1970). An electron microscopic study of the presence or absence of neuraminic acid in envelope viruses. Virology 42, 115-118.

LAEMMLI, U. K. (1970). Cleavage of structural proteins during the assembly of the heat of bacteriophage T4. Nature (London) 227, 680-685.

LAMB, R. A., ETKIND, P. R., and ChOPPIN, P. W. (1978). Evidence for a ninth influenza viral polypeptide. Virology 91, 6078.

LASKEY, R. A., and MmLS, A. D. (1975). Quantitative film detection of ${ }^{3} \mathrm{H}$ and ${ }^{14} \mathrm{C}$ in polyacrylamide gels by fluorography. Eur. J. Biochem. 56, 335-341.

MAASSAB, H. F. (1967). Adaptation and growth characteristics of influenza virus at $25^{\circ} \mathrm{C}$. Nature (London) 213, 612-614.

MAASSAB, H. F. (1969). Biologic and immunologic characteristics of cold-adapted influenza virus. $J$. Immunol 102, 728-732.

MAASSAB, H. F. (1970). Development of variants of influenza virus. In "The Biology of Large RNA Viruses" (R. D. Barry and B. W. J. Mahy, eds.), pp. 542-566. Academic Press, New York.

MAASSAB, H. F. (1975). Properties of influenza virus 'cold' recombinants. In "Negative Strand Viruses" (B. W. J. Mahy and R. D. Barry, eds.), Vol. 2, pp. 755-763. Academic Press, New York.

MAASSAB, H. F., CoX, N. J., MURPHY, B. R., and KENDAL, A. P. (1977). Biological, genetic and biochemical characterization of a cold-adapted recombinant $A /$ Victoria/3/75 virus and its evaluation in volunteers. In "International Symposium on Influenza Immunization II." Developments in Biological
Standardization, Vol. 39, pp. 25-31. S. Karger, Basel.

MaAssab, H. F., DeBorde, D. C., Cox, N. J., and KENDAL, A. P. (1981). Development of cold recombinants of influenza virus as live virus vaccines. In "Genetic variation among influenza viruses" (D. Nayak, ed.), pp. 617-638. Academic Press, New York.

MAasSAB, H. F. Francis, T., JR., DAVENPORT, F. M., HenNessy, A. V., MinUSE, E., and ANDERSON, G. (1969). Laboratory and clinical characteristics of attenuated strains of influenza virus. Bull. WHO 41, 589-594.

MaAsSab, H. F., Spring, S. B., Kendal, A. P., and MONTO, A. S. (1978). Biologic characteristics of influenza virus recombinants derived at suboptimal temperatures. In "Negative Strand Viruses and the Host Cell" (B. W. J. Mahy and R. D. Barry, eds.), pp. 721-732. Academic Press, New York.

MASSICOT, J. G., MURPhY, B. R., VAN WYKe, K., Huang, K. Y., and Chanock, R. M. (1980). ts P1 and $P 3$ genes are responsible for satisfactory level of attenuation of ts-1A2 recombinants bearing H1N1 or H3N2 surface antigens of influenza A virus. Virology 106, 187-190.

Moritx, A. J., Kunz, C., Hofman, H., Liehl, E., REEVE, P., and MAASSAB, H. F. (1980). Studies with a cold-recombinant $A /$ Victoria/3/75 (H3N2) virus. II. Evaluation in adult volunteers. J. Infect. Dis. $142,857-860$.

Murphy, B. R., Chanock, R. M., Douglas, R. G., BetTs, R. F., Waterman, D. H., Holley, H. P., JR., Hoover, D. L., SuWANaGood, S., NALIN, D. R., and LEVINE, M. M. (1980a). Temperature-sensitive mutants of influenza A virus: Evaluation of the Alaska/77-5s-1A2 temperature-sensitive recombinant virus in seronegative adult volunteers. Arch. Virol 65, 169-173.

MURPHY, B. R., HOLLY, H. P., BERQUIST, E. J., LEVINE, M. M., Spring, S. B., MaAssab, H. F., Kendal, A. P., and Chanock, R. M. (1979). Cold-adapted variants of influenza $A$ viruses: Evaluation in adult seronegative volunteers of $\mathrm{A} / \mathrm{Scotland} / 840 / 74$ and A/Victoria/3/75 cold-adapted recombinants derived from the cold-adapted $\mathrm{A} / \mathrm{Ann}$ Arbor/6/60 strain. Infect. Immun 23, 253-259.

MURPHY, B. R., MAASSAB, H. F., WOOD, F. T., JR., and CHANoCK, R. M. (1981). Characterization of the temperature-sensitive phenotype of the A/Ann Arbor $/ 6 / 60$ cold-adapted virus and its recombinants. Infect. Immun. 32, 960-963.

MURPHY, B. R., MARGRET, B. R., GoRDON, R. D. JR., BETTS, R. F., COUCH, R. B., CATE, T. R., JR., CHANock, R. M., Kendal, A. P., MaAssab, H. F., SUWANAGOOL, S., Sotman, S. B., Cisneros, L. A., ANThony, W. C., NALIN, D. R., and LEVINE, M. M. (1980b). Evaluation of influenza A/Hong Kong/ 
123/77 (H1N1) ts-1A2 and cold-adapted recombinant viruses in seronegative adult volunteers. Infect. Immun. 29, 348-355.

Murphy, B. R., Markoff, L. J., Chanock, R. M., SpRING, S. B., MAASSAB, H. F., KENDAL, A. P., CoX, N. J., Levine, M. M., Douglas, R. G., BeTTS, R. F., JR., CoUCH, R. B., and CATE, T. R., JR. (1980c). Genetic approaches to attenuation of influenza $A$ virus for man. Phil. Trans. $R$. Soc. London. 288, 401415.

Murphy, B. R., Wood, F. T., Massicot, J. G., ChaNOCK, R. M. (1978). Temperature-sensitive mutants of influenza $A$ virus. XV. The genetic and biological characterization of a recombinant influenza virus containing two ts lesions produced by mating two complementing, single lesion ts mutants. Virology 88, 231-243.

MurPhy, B. R., WoOD, F. T., Massicot, J. G., and Chanock, R. M. (1980d). Temperature-sensitive mutants of influenza $A$ virus. Transfer of the two ts-1A2 ts lesions present in the Udorn/72-ts-1A2 donor virus to the influenza A/Alaska/6/77 (H3N2) wild-type virus. Arch. Virol 65, 175-186.

Palese, P., Baez, M., Zazar, J. J., Ellioto, R. M., and YouNG, J. F. (1981). Genetic structure of RNA 8 of influenza A viruses. In "Genetic Variation Among Influenza Viruses" (D. Nayak, ed.), pp. 127140. Academic Press, New York.

Palese, P., and SCHULMAN, J. L. (1976). Mapping of the influenza virus genome: Identification of the hemagglutinin and neuraminidase genes. Proc. Nat. Acad. Sci. USA 73, 2142-2146.

Palmer, D. F., Dowdle, W. R., Coleman, M. T., and SCHILD, G. C. (1975). “Advanced laboratory tech- niques for influenza diagnosis." U. S. Department of Health, Education, and Welfare. C. D. C.

Peacock, A. C., and Dingman, C. W. (1968), Molecular weight estimation and separation of ribonucleic acid by electrophoresis in agarose-acrylamide composite gels. Biochemistry 7, 668-674.

Peluso, R. W., Lamb, R. A., and Choppin, P. W. (1977). Polypeptide synthesis in simian virus 5-infected cells. J. Virol 23, 177-187.

PONS, M. W. (1976). A reexamination of influenza single- and double-stranded RNAs by gel electrophoresis. Virology 69, 789-792.

Reeve, P., Almond, J. W., Felse'nreich, V., PiberMAN, M., and MAASSAB, H. F. (1980). Studies with a cold-recombinant $A / V i c t o r i a / 3 / 75$ (H3N2) virus. I. Biologic, genetic, and biochemical characterization. J. Infect. Dis. 142, 850-856.

Scholtissek, C., Harms, E., Rohde, W., ORLich, M., and RoTT, R. (1976). Correlation between RNA segments of fowl plaque virus and their corresponding gene functions. Virology 74, 332-344.

Spring, S. B., MaAsSab, H. F., Kendal, A. P., MurPHY, B. R., and CHANOCK, R. M. (1977a). Coldadapted variants of infuenza virus $A$. I. Comparison of the genetic properties of ts mutants and five cold-adapted variants of influenza virus $A$. Virology 77, 337-343.

Spring, S. B., MaAssab, H. F., Kendal, A. P., MurPHY, B. R., and CHANOCK, R. M. (1977b). Coldadapted variants of influenza $A$. II. Comparison of the genetic and biological properties of ts mutants and recombinants of the cold-adapted A/AA/6/60 strain. Arch. Virol. 55, 233-246. 